\title{
An Inquiry into the NEST Program in Relation to English Teaching and Learning in Taiwanese Primary Schools
}

\author{
Wen-Hsing Luo ${ }^{1}$ \\ ${ }^{1}$ Department of English Instruction, National Hsinchu University of Education, Taiwan \\ Correspondence: Wen-Hsing Luo, Department of English Instruction, National Hsinchu University of Education, \\ 521 Nanda Rd., 30014 Hsinchu City, Taiwan. E-mail: wluo@mail.nhcue.edu.tw
}

Received: August 29, 2013 Accepted: October 18, 2013 Online Published: December 5, 2013

doi:10.5539/elt.v7n1p149 URL: http://dx.doi.org/10.5539/elt.v7n1p149

\begin{abstract}
This study aims to explore the Native English-Speaking Teacher (NEST) Program in relation to teachers' instruction and students' learning of English in primary schools in Taiwan. Inviting native English-speakers to teach English in the school system is not an unusual practice in the Asia-Pacific region. As the practice of including NESTs in the school system has become prevalent in Taiwan, alongside other Asian countries, its significance cannot be overlooked. It is worthwhile to look into the impact of NEST programs on local English teachers and students in context. Through interviewing, class observation and questionnaire, this study finds that the NEST Program in Taiwan did not have a considerable impact on teachers' instruction, whereas its effect on teachers' professional development was mainly concerning English language proficiency. As for students' learning, the NESTs in the Program served as a language model in the classroom and were able to arouse students' motivation at the beginning of the school year. Nevertheless, the teachers and the students had unfavorable perceptions of the NESTs due to their unexpected leave without notice. In light of the research findings, the author makes suggestions on the NEST Program.
\end{abstract}

Keywords: English learning, English teaching, NEST programs, primary schools

\section{Introduction}

In 2001, a far-reaching change in English education in Taiwan occurred. Namely, formal English instruction would start at grade five (Note). In the same year, Hsinchu City, an industrial city in the northern part of Taiwan, launched the first ever Native English-Speaking Teacher (NEST) Program, i.e., including NESTs in primary schools, in this country as a means to promote primary English education. Actually, inviting native English-speakers to teach English in the school system is not an unusual practice in the Asia-Pacific region. Examples as such include the Primary Native-Speaking English Teacher Scheme (PNET) in Hong Kong, the Japan Exchange and Teaching Program (JET), and the English Program in Korea (EPIK). As the practice of including NESTs in the school system has become prevalent in Taiwan, alongside other Asian countries (e.g., China, Korea and the United Arab Emirates), its significance cannot be overlooked. It is worthwhile to look into how the NEST programs affect local English teachers and students in context.

Previous studies in this field were mainly concerned with the management of NESTs or collaborative teaching of English by NESTs and local English teachers (e.g., Carless, 2006a, 2006b; Choi, 2001; Chou, 2005; Luo, 2010). Little research was conducted regarding the program in relation to local English teachers' instruction and professional development as well as students' learning. The present study is a response to the call for more research addressing these issues. Through interviewing, class observation and a student survey, this study aims to seek answers to the following questions:

1) From local teachers' perspective, how does the NEST Program affect their instruction in Taiwanese primary schools?

2) From local teachers' perspective, how does the NEST program affect their professional development?

3) From teachers' and students' perspective, how does the NEST Program affect students' learning of English in Taiwanese primary schools?

Additionally, the author discusses how well the program's effects as such are justified in accordance with the goals set for the program by the Ministry of Education in Taiwan. 


\section{NEST Programs in Asia}

\subsection{The PNET Scheme}

A NEST program refers to a language teacher policy made by governments, which results in the inclusion of NESTs as a major source of English instruction in the school system (Sommers, 2012). In Hong Kong, the inclusion of trained and experienced native-speaking teachers (NETs) in secondary schools started in 1987. Presently, there are two kinds of NET schemes in Hong Kong: the Secondary and the Primary NET Schemes. Clearly stated in the guidelines for NET deployment posted on the website of the Hong Kong Education Bureau (EDB), the PNET Scheme aims to "(a) provide an authentic environment for students to learn English; (b) develop students' interest in learning English and establish the foundation for life-long learning; (c) help local teachers develop innovative learning and teaching methods, materials, curricula and activities suited to the needs of students; and (d) disseminate good practices in language learning and teaching developed within the Scheme through teacher development programs such as experience-sharing seminars, workshops and networking activities" (Hong Kong EDB Circular No. 8/2002 cited in NET Deployment Guidelines, 2009).

The goals of the PNET Scheme are to promote students' learning and teachers' teaching of English language in primary schools in Hong Kong. Professional development of local teachers is a concern of the Scheme. However, a detailed evaluation project commissioned by the Hong Kong Education and Manpower Bureau (Griffin, Woods, Storey, Wong \& Fung, 2007) revealed that NETs in the Scheme seemed to be regarded as supplementary teaching resources and the role of NETs was not defined clearly. To address these issues, Griffin et al. (2007) recommended the Scheme formalize the NET's role and introduce a monitoring process within the school. They also suggested that an accountability procedure should be implemented for the schools, NETs and local English teachers in the Scheme. By comparison, a study by Carless (2006a) found that NETs in the Scheme encountered tensions in team-teaching situations and were uncertain about their role in relation to the professional development of local English teachers. His study indicated that promoting collaborative teaching and achieving continuous professional development are challenges to the Scheme.

\subsection{The JET Program}

The Japan Exchange and Teaching (JET) Program was established in 1987, and since then the JET Program has invited overseas university graduates to assist in international exchanges and foreign language education in local governments, boards of education and primary as well as secondary schools throughout Japan. The JET Program is managed under the auspices of local governments in cooperation with the Ministry of Education, Culture, Sports, Science and Technology (MEXT), the Ministry of Internal Affairs and Communications (MIC), the Ministry of Foreign Affairs (MOFA), and the Council of Local Authorities for International Relations (CLAIR). As a government-sponsored and centralized policy, the JET Program receives support from the CLAIR and the three ministries, which is essential to JET participants and the contracting organizations that employ them (JET Program website, 2012). The JET Program aims to "(a) increase mutual understanding between Japanese people and people of other nations, (b) promote internationalization of local communities in Japan by helping to improve foreign language education, and (c) develop international exchanges at the community level" (JET Program website, 2012). Following the guidelines for the deployment of JET participants, NESTs, also called assistant language teachers (ALTs), are placed in local boards of education or public schools (including primary and secondary schools), and are engaged in language instruction under the guidance of language teacher consultants or Japanese teachers of foreign languages. ALTs' responsibilities include "(1) team teaching or assisting with classes taught by Japanese teachers of English (JTEs); (2) assisting in the preparation of teaching materials; and (3) participating in extracurricular activities with students, such as English clubs and sports teams" (JET Program website, 2012).

Previous research has revealed drawbacks of the JET Program such as lack of training, institutional conflicts (Crook, 2001), and the uncertainty of the roles that team teachers played (Kachi \& Lee, 2001). Additionally, Carless (2006b) found that as most of ALTs in the JET Program did not have teaching qualifications, their impact on improving English language education in Japan might be reduced.

\subsection{EPIK}

Being a NEST program, the English Program in Korea (EPIK) aims to "(1) foster primary- and secondary-level students' English communication ability, (2) provide English conversation training for public school English teachers, (3) develop English textbooks and teaching materials, (4) improve and expand English teaching methodologies, (5) encourage cultural awareness between Koreans and EPIK teachers, and (6) better Korea's image abroad" (EPIK website, 2012). The main purpose of the EPIK is to improve English education in Korea. According to the contract (EPIK website, 2012), EPIK teachers need to assume the following duties: "(1) to 
assist Korean teachers with their English classes and/or jointly conduct English classes with Korean teachers, and lead extracurricular activities; (2) to prepare teaching materials and lesson plans for English classes; (3) to assist with the development and creation of teaching materials related to English language education; (4) to assist with activities related to English language education and other extracurricular activities, such as conducting teacher training and working at English camps; (5) to conduct English conversational classes/courses for Korean teachers and students; and (6) to perform other duties as designated by the Provincial Office of Education (POE), such as offering English programs during the school vacation." The responsibilities that EPIK teachers undertake pertain directly to English teaching and teacher training. However, the majority of EPIK teachers did not have teaching experience in teaching English as a foreign/second language (TEFL/TESL) (Choi, 2001) and only 13\% of them were certified teachers (JoongAng Daily, 2009). It is debatable that EPIK teachers who do not have teaching qualifications are capable of assuming such duties as providing teacher training and conducting English conversational courses for Korean English teachers.

\subsection{The NEST Program in Taiwan}

In 2001, Hsinchu City launched the first-ever NEST Program in Taiwan. Contrasted with the JET Program and the EPIK, which are sponsored by their respective central governments, the NEST Program in Taiwan is not a centralized policy, and decisions on the implementation of the program are left to the individual cities/counties. In 2004, NESTs were recruited by the Ministry of Education (MOE) in Taiwan, separately from those recruited by local governments, to fulfill a shortage of qualified English teachers at primary schools in remote areas. Since then, NESTs have been included in primary schools in Taiwan through two tracks: the local governments and the MOE (the central government).

According to the guidelines stated by the MOE, the NEST Program in Taiwan aims to "(a) promote teamwork in English teaching as well as improve the English learning environment for students in remote areas, (b) innovate local English teachers' concepts of English language education through exchanging ideas about teaching methods and materials between local teachers and NESTs, (c) improve students' learning and communication ability in English, and (d) facilitate cultural exchanges between Taiwan and other countries and advance other countries' understanding of Taiwanese culture" (MOE website, 2003). Job descriptions for NESTs are as follows: "(a) to support collaborative teaching of English and develop effective learning activities, (b) to support remedial instruction for students and promote conversational English, (c) to support the research and development of supplementary materials, (d) to promote current concepts of English teaching through teaching demonstrations and school visits, and (e) to assume other duties related to English learning and cultural exchanges" (MOE website, 2003). While decisions on the NEST Program policy are made by the local governments, the guidelines mentioned above serve as a framework for the program in individual cities/counties where it is implemented. By and large, the function of the NEST Program in Taiwan is twofold: educational and cultural. It is clearly stated in the guidelines by the MOE that teachers in the NEST Program are to work with Taiwanese teachers of English (TTEs) as an English teaching team at the school and to support the research and development of English teaching methods and materials.

During the past decade, studies in relation to the NEST Program in Taiwan have been seen (e.g., Cheng, 2003; Chou, 2005; Lin, 2001; Luo, 2010; Peng, 2003); yet, most of the studies focused on the teaching practice by the NESTs in the program. NEST programs, although known by different names, have become prevalent in Asian countries. To shed light on how to utilize a program of this kind to the fullest, research on the significance of the program with respect to its impact on local English teachers and students in context is needed.

\section{The Study}

This study, lasting for one year, was conducted in an agricultural county located in north Taiwan. The NEST Program in this county was first launched in 2010 with only one NEST. In 2012, six NESTs were included in this county's NEST Program. Due to the small number of NESTs in the program, the deployment of NESTs to the primary schools in this county was decided by the county government and not every school was assigned a NEST. To investigate the program in relation to its effects on local English teachers and students, three kinds of instruments were used to solicit data: interviewing, class observation and questionnaire. Four TTEs, Lee, Lin, $\mathrm{Wu}$, and Chen (all these names are pseudonyms), who taught at the primary schools in this county were invited to participate in the study on a voluntary basis. Each of the teacher participants had three individual interviews throughout this study (see interview protocol in Appendix A). Each of the individual interviews lasted about one hour. All the interviews were tape-recorded and transcribed. The author also conducted a formal non-participant observation in the classes co-taught by the teachers and their native co-teachers once every other month for one period of class (i.e., 40 minutes) (see observation focus in Appendix B). There were 16 observations in total. 
Interviews and class observations were conducted to explore the local teachers' perceptions of the program regarding its impact on their teaching and professional development. Interview data collected from the teachers were also used to explore the program's impact on students' learning from the teachers' perspective. Additionally, a student survey was conducted to collect information about students' attitude toward NESTs' instruction and the program. The valid sample size was 249 students of grades five and six of the classes co-taught by the TTEs and NESTs which were observed by the author.

\section{Discussion of Findings}

In this section, findings are discussed in relation to the research questions: (1) the effect of the NEST Program on local teachers' instruction, (2) the effect of the program on local teachers' professional development, and (3) the effect of the program on students' learning.

\subsection{The NEST Program in Relation to Local Teachers' Instruction}

\subsubsection{Becoming Aware of One's English Teaching in the Classroom}

Interview data show that because of the NEST Program, Wu became self-conscious of the accuracy of the lessons she taught to students. She commented:

"Because of the NEST Program, I become self-conscious of what I teach to students. I am concerned if the English language I teach is correct, such as pronunciation and word use. From the NEST, I learned the correct English pronunciation, proper use of daily English and correct use of classroom English." (Excerpts from the first interview with $\mathrm{Wu}$ )

While Wu became aware of the accuracy of the content she taught in the classroom, Lin remarked that she became aware of students' pronunciation problems because her native co-teacher pointed out certain phoneme difficulties which her students encountered. She said:

"The NEST has found some phoneme problems that are less noticed by the students such as "s" and " $\mathrm{t}$ " ending sounds and that reminds me I should pay more attention to students' pronunciation practice." (Excerpts from the second interview with Lin)

\subsubsection{Whole English Instruction}

Another effect of the NEST Program was English-medium instruction given by the NESTs. Lin remarked:

"I think the NESTs provide English-medium instruction for students in the classroom, which is good. Other than that, the program doesn't have an effect on my teaching in the classroom. The NESTs have no teaching experience in Taiwan. They didn't shed new lights on lesson planning, activity design or the use of smart board." (excerpts from the first interview with Lin)

"Except that the NEST is able to give English-medium instruction, the way of her teaching is very much the same as mine."(Excerpts from the second interview with Lin)

\subsubsection{Unfavorable Perceptions of NESTs}

Before the end of the first semester, two NESTs left the program without completing the contract. Due to their unexpected leave, the TTEs had unfavorable perceptions of NESTs. As Wu commented:

"I think the NEST is very irresponsible. The syllabus had already been decided before the school began; there is one period of English class taught by me and the NEST. He left the program without giving any notice, and I needed to change the syllabus entirely. I managed to adjust the lessons and follow the new syllabus all right, but I was not prepared for anything like this from my co-teacher. I need preparation time for adjusting the lessons." (Excerpts from the third interview with $\mathrm{Wu}$ )

Another TTE, Chen, was angry and disappointed when she found out that her native co-teacher suddenly left the program. She made comments on the management of NESTs:

"Because of this incident, I find that the mechanism for managing NESTs is not good. There is no system for managing NESTs effectively and appropriately. I think the management system should involve the government, the school administration and the Taiwanese teachers...." (Excerpts from the third interview with Chen)

The study shows that the TTEs became aware of the pronunciation problems that the students encountered (e.g., Lin) and they were self-concerned about the accuracy of the lessons given to the students (e.g., Wu). The teachers did not find a substantial effect of the NEST Program on their teaching in the classroom. On the contrary, the TTEs (e.g., Wu and Chen) had unfavorable perceptions of the NESTs due to their unexpected leave. It is also found that the NESTs did not have experience of teaching English in Taiwan and therefore were unable 
to shed new lights for the TTEs (Lin's remarks in the first interview). The interview data indicate that the effects of the NEST Program did not tally with its goals set by the MOE (2003), for instance, promoting teamwork in English teaching and developing effective learning activities. However, field notes taken in class observations show that the NESTs led instruction in co-teaching classes. TTE, Wu, gave a plausible explanation for this observation. She said (in the first interview) "there is only one period of co-teaching class each week, and there are two periods of classes taught by me alone. So I let the NEST lead the lesson and students can receive native input of English."

\subsection{The NEST Program in Relation to Local Teachers' Professional Development}

\subsubsection{Improvement of English Proficiency}

All of the teacher participants remarked that their spoken English ability was improved after having worked with the NESTs. Chen and Wu said, respectively:

"Because of working with the NEST, my English speaking ability has been improved...." (Excerpts from the first interview with Chen)

"Because of the NEST Program, I have to work with the NEST, my English pronunciation has been improved a lot." (Excerpts from the second interview with $\mathrm{Wu}$ )

Lin commented that her native co-teacher was like an English tutor to her. Working with the NEST helped her to learn correct use of English. She said:

"She is like my English tutor. My favorite part of working with her is, from her, I learned correct use of English, especially word usage. Working with her helps me to learn how to use English words precisely, and it is helpful for my teaching." (Excerpts from the first interview with Lin)

\subsubsection{Research of Teaching Materials and Resources}

Interview data show that the TTEs learned how to search teaching resources from their native co-teachers. For instance, $\mathrm{Wu}$ commented:

"The NEST is good at searching teaching resources websites, which I found quite useful. I've learned from him about searching teaching materials and resources on the Internet." (Excerpts from the second interview with Wu)

In comparison, Chen mentioned that from her native co-teacher, she learned how to evaluate the textbooks she used.

"The NEST pointed out mistakes in the textbooks and gave suggestions, especially on sentence patterns that do not conform to the use by native speakers... I became to examine the content of the textbooks more critically." (Excerpts from the first interview with Chen)

\subsubsection{Understanding of Holidays in English-Speaking Countries}

Lee commented that his understanding of holidays in English-speaking countries was enhanced after working with his native co-teacher.

"I think because of working with the NEST, I gain a better understanding of holidays in English-speaking countries, for instance, St. Patrick's Day. I'd never heard about it before. When we discuss holiday teaching activities, the NEST provides a different perspective that I rarely think about, although he doesn't help improve my teaching skills." (Excerpts from the third interview with Lee)

The TTEs unanimously commented that their English proficiency (e.g., spoken English and use of English words) was improved after having worked with the NESTs. As the teachers needed to discuss lessons with the NESTs, they had more opportunities to practice English than they used to. Consequently, their English proficiency was improved. Comments by $\mathrm{Wu}$ indicate that the NESTs supported the research of supplementary teaching resources, which is one of the job requirements for the NESTs (MOE website, 2003). However, the effects of the NESTs on the TTEs did not match up with the aims for the NEST Program in terms of development of teacher professionalism, for instance, innovating local English teachers' concepts of English education and promoting current trends of English teaching. In line with the study by Carless (2006a) on the PNET Scheme in Hong Kong, this study shows that the NEST Program did not help to promote teaching innovation and continuous professional development. 


\subsection{The NEST Program in Relation to Students'Learning: Teachers' Perspective}

\subsubsection{NESTs Being a Language Model}

The TTEs considered the foremost effect of the NESTs on students' learning was that they provided native input and served as a language model in the classroom. Lee remarked:

"The NEST serves as a language model for the students in the classroom. When they try to figure out how to express themselves in English, a language model is available for them... They can practice with the NEST and find out how native speakers use the language." (Excerpts from the first interview with Lee)

\subsubsection{Tolerance for Students' Mistakes}

The TTEs commented that the NESTs were tolerant of students' ideas and mistakes. As Lin commented:

'I think the NEST is more tolerant of students' mistakes. She is tolerant of students' creative ideas, and will correct their mistakes in an indirect manner. Usually, I am more direct and straightforward when dealing with students' mistakes." (Excerpts from the second interview with Lin)

Wu also said (in the first interview) that her native co-teacher was patient when dealing with students' mistakes. The NEST gave the students more waiting time and did not correct the students' mistakes immediately.

\subsubsection{Motivating Student Learning}

The TTEs remarked that the students were motivated because the presence of a NEST in the classroom was a novelty for the students. Wu said:

"In the beginning of the semester, the students were motivated because of the presence of the NEST in the classroom. Now it seems that the novelty is wearing off, and the students become unmotivated again." (Excerpts from the second interview with $\mathrm{Wu}$ )

Chen made similar comments:

"The NEST is quite friendly to the students. After the class, he will talk to them. So far, he has been able to arouse students' motivation in learning English. But, when the students become familiar with the NEST's teaching style, they will become bored." (Excerpts from the second interview with Chen)

\subsubsection{Unfavorable Effects on Students' Learning}

The NEST's sudden leave resulted in the TTEs' unfavorable perceptions of the NESTs. Similarly, it had negative effects on students. Chen remarked:

"It caused a commotion among the students when the NEST didn't show up for the class... Some students even got angry when they found that the NEST left without giving any notice. This incident adversely affected students' right to English learning and had a negative effect on students." (Excerpts from the third interview with Chen)

The TTEs' comments show that by and large the NESTs motivated student learning and were considered as a language model for the students in the classroom. Yet, observation notes indicate that the lessons given by the NESTs mainly focused on drills and imitation and very little, if there was any, on meaningful speaking practice. It appears that the NESTs failed to achieve the aims set for the program in terms of improving students' communication ability in English, supporting remedial instruction for students and promoting conversational English (the MOE website, 2003).

\subsection{The NEST Program in Relation to Students' Learning: Students' Perspective}

As mentioned earlier, a student survey was conducted in the co-teaching classes of grades five and six which were observed by the author to explore the students' perceptions of the NESTs and their instruction. In addition to background information such as gender, students' grade, years of learning English and years of being taught by NESTs, the student survey consists of 10 items using a 5-point Likert scale, indicating from strongly agree to strongly disagree. These items include:

1) I like English classes.

2) I like English classes taught by the NEST.

3) I like English classes taught by the TTE.

4) Because of the NEST, I become to like English classes more than I used to.

5) Because of the NEST, I find English classes interesting. 
6) Because of the NEST, I become not afraid of English classes.

7) When seeing the NEST on campus, I will say hi to him/her.

8) Because of the NEST, I become not afraid of speaking in English.

9) Because of the NEST, I realize that English is a tool for communication with foreigners.

10) I hope there are more NESTs at school.

The survey results (see Table 1) show that the students' attitude toward NESTs was mostly positive, i.e., indicating strongly agree or agree on the survey items. For instance, on items, "I like English classes taught by the NEST" (58\%), "when seeing the NEST on campus, I will say hi to him/her" (54\%), "because of the NEST, I realize English as a tool of communication with foreigners" (67\%) and "I hope there are more NESTs at school" (54\%), more than half of the questionnaire respondents replied strongly agree or agree. Means of these items are $3.795,3.819,3.923$, and 3.771, respectively. These results indicate that the students valued the presence of NESTs at school and became to realize the strength of English as a communicative tool rather than a school subject. Nevertheless, it is found that on all of the survey items, except for items 7 and 9, more than one-third of the replies were neutral (i.e., indicating no opinions). In particular, on items, "because of the NEST, I become not afraid of English classes" and "because of the NEST, I become not afraid of speaking in English," $44 \%$ of the respondents replied no opinions. Means of these two items fell on 3.353 and 3.325, which were lower than those of the other items. It is suggested that while the students acknowledged the value of NESTs, they had not as yet overcome a fear of English classes and speaking in the language even if being taught by NESTs. The finding that more than one-third of the respondents held a neutral attitude toward the NESTs and their instruction indicates that there was room for improvement in the NEST Program concerning its effect on students' learning of English.

Table 1. Percentages and means of students' replies to the survey items on a 5-point Likert scale (sample size: 249 students)

\begin{tabular}{|c|c|c|c|c|c|c|c|}
\hline $\begin{array}{l}\text { items } \\
\text { degree }\end{array}$ & $\begin{array}{l}\text { Strongly } \\
\text { Agree }(=5)\end{array}$ & $\begin{array}{l}\text { Agree } \\
(=4)\end{array}$ & $\begin{array}{l}\text { No Opinions } \\
(=3)\end{array}$ & $\begin{array}{l}\text { Disagree } \\
(=2)\end{array}$ & $\begin{array}{l}\text { Strongly } \\
\text { Disagree }(=1)\end{array}$ & Mean & SD \\
\hline 1. I like English classes. & $23 \%$ & $27 \%$ & $34 \%$ & $8 \%$ & $8 \%$ & 3.506 & 1.157 \\
\hline $\begin{array}{l}\text { 2. I like English classes taught } \\
\text { by the NEST. }\end{array}$ & $30 \%$ & $28 \%$ & $36 \%$ & $3 \%$ & $3 \%$ & 3.795 & 0.997 \\
\hline $\begin{array}{l}\text { 3. I like English classes taught } \\
\text { by the TTE. }\end{array}$ & $19 \%$ & $24 \%$ & $45 \%$ & $6 \%$ & $6 \%$ & 3.449 & 1.054 \\
\hline $\begin{array}{l}\text { 4. Because of the NEST, I } \\
\text { become to like English classes } \\
\text { more than I used to. }\end{array}$ & $22 \%$ & $26 \%$ & $38 \%$ & $9 \%$ & $5 \%$ & 3.514 & 1.082 \\
\hline $\begin{array}{l}\text { 5. Because of the NEST, I find } \\
\text { English classes interesting. }\end{array}$ & $25 \%$ & $26 \%$ & $37 \%$ & $9 \%$ & $3 \%$ & 3.594 & 1.055 \\
\hline $\begin{array}{l}\text { 6. Because of the NEST, I } \\
\text { become not afraid of English } \\
\text { classes. }\end{array}$ & $18 \%$ & $21 \%$ & $44 \%$ & $12 \%$ & $5 \%$ & 3.353 & 1.072 \\
\hline $\begin{array}{l}\text { 7. When seeing the NEST on } \\
\text { campus, I will say hi to him/her. }\end{array}$ & $26 \%$ & $38 \%$ & $31 \%$ & $2 \%$ & $3 \%$ & 3.819 & 0.935 \\
\hline $\begin{array}{l}\text { 8. Because of the NEST, I } \\
\text { become not afraid of speaking in } \\
\text { English. }\end{array}$ & $15 \%$ & $24 \%$ & $44 \%$ & $12 \%$ & $5 \%$ & 3.325 & 1.021 \\
\hline $\begin{array}{l}\text { 9. Because of the NEST, I } \\
\text { realize that English is a tool for } \\
\text { communication with foreigners. }\end{array}$ & $32 \%$ & $35 \%$ & $29 \%$ & $2 \%$ & $2 \%$ & 3.923 & 0.941 \\
\hline $\begin{array}{l}\text { 10. I hope there are more NESTs } \\
\text { at school. }\end{array}$ & $33 \%$ & $21 \%$ & $38 \%$ & $5 \%$ & $3 \%$ & 3.771 & 1.043 \\
\hline
\end{tabular}


The results of the student survey corroborate the teachers' perceptions and the author's observation of the NEST Program's effects on students' learning. Namely, while the program succeeded in arousing students' motivation in learning English, it did not achieve goals set by the MOE with regard to improving students' communication ability in English and promoting conversational English.

\section{Suggestions}

In light of the above discussion, the author wishes to make the following suggestions. First, recruitment of NESTs with a TESL/TEFL certificate is needed. The study shows that there was no substantial impact of the NEST Program on teachers' teaching in the classroom. The NESTs being hired in the program did not have a TESL/TEFL background and could not shed new light on English teaching as the TTEs expected. There is a need for the government to recruit NESTs with a TESL/TEFL background, especially those who have experience of TEFL at the primary level.

Second, it is suggested to rethink the focus of teacher professional development for TTEs. The study indicates that the effects of the program on teachers' professional development were related to English language proficiency, knowledge of teaching resources and understanding of holidays in English-speaking countries. The author suggests that professional development schemes should address the needs of TTEs in the collaborative teaching context, for instance, the needs of improving English proficiency and cultural understanding. Furthermore, the development of TTEs' English proficiency should emphasize English-medium instructional skills, which the TTEs (e.g., Lin) were not equipped with.

Third, the author suggests NESTs interact with students in and out of the classroom in various ways so as to sustain students' motivation and provide native input for them. The study shows that the effects of the NEST Program on students' learning were mainly positive in terms of arousing students' motivation and providing native input. However, the TTEs found that the students became unmotivated when the novelty of having a NEST in the classroom worn off (as Wu commented) or after they became familiar with the NEST's teaching styles (as Chen remarked). The survey results also indicate that approximately one-third of the students held a neutral attitude toward the NESTs and their instruction. To improve and sustain students' motivation, the author suggests NESTs interact with students not only in the class but also out of the classroom through various ways, such as student club activities, English contests and school events. Interacting with NESTs in English out of the classroom helps students to recognize English as a tool for international communication and motivates them to learn English in a manner that is meaningful for them.

Finally, a mechanism for managing the NEST Program is called for. The negative impact on the teachers and the students owing to the NESTs' unexpected leave brings home to the TTEs (as Chen commented) the importance of establishing a sound mechanism for managing the NEST Program. All the parties involved in the implementation of the program, i.e., the government, the school administration and TTEs, should be included in the management system to monitor and evaluate the ongoing improvement of the program.

\section{Conclusion}

This study examined the NEST Program in relation to teachers' instruction and professional development as well as students' learning of English in primary schools in Taiwan. It shows that the NEST Program did not have a considerable effect on the teachers' instruction, whereas its impact on teachers' professional development was mainly concerning English proficiency. As for the program's effects on student learning, the NESTs served as a language model for the students and were able to arouse students' motivation at the beginning of the school year. Nevertheless, the teachers and the students had unfavorable perceptions of the NESTs due to their unexpected leave. As a growing number of native speakers of English, whether or not teacher-certified, are joining the English teaching profession in school systems in Asian countries, continuing evaluation of NEST programs of this kind is needed to ensure and sustain the quality and efficacy of the programs. Policy makers need to scrutinize potential outcomes of the implementation of NEST programs and bear in mind that it is when students' learning is optimized that the purposes of these programs can best be served. To better understand the implementation of NEST programs in context, the author wishes to call for studies on how the aims of these programs in relation to teachers' instruction and students' learning have been achieved and how to improve the programs accordingly.

\section{Acknowledgements}

The author thanks Taiwan's National Science Council for the research fund. She also expresses her gratitude to the teacher participants. This study wouldn't be possible without their help. 


\section{References}

Carless, D. (2006a). Collaborative EFL teaching in primary schools. ELT Journal, 60(4), 328-335. http://dx.doi.org/10.1093/elt/ccl023

Carless, D. (2006b). Good Practices in Team Teaching in Japan, South Korea and Hong Kong. System, 34(3), 341-351. http://dx.doi.org/10.1016/j.system.2006.02.001

Cheng, H. F. (2003). Wai Ji Jiao Shi Dzai Miao Li Hsien Dan Zan Ying Yu Jiao Hsue Chi Yien Jiou [A study of the employment of foreign English teachers as English teachers in Miao-Li Prefecture]. (Unpublished master's thesis, National Taipei Teachers College, Taiwan).

Choi, Y. (2001). Suggestions for the re-organization of English teaching program by native speakers in Korea. English Teaching, 56(1), 101-122.

Chou, M. Y. (2005). Hsin Chu Shi Guo Ming Hsiao Ying Yu Hie Tung Jiao Hsue Chi Yien Jiou [A study of English collaborative teaching at elementary schools in Hsinchu City]. (Unpublished master's thesis, National Taipei Teachers College, Taiwan).

Crooks, A. (2001). Professional development and the JET program: Insights and solutions based on the Sendai City program. JALT Journal, 23(1), 31-46.

EPIK home page. (2012). Retrieved November 28, 2012, from http://www.epik.go.kr/

Griffin, P., Woods, K., Storey, P., Wong, E. K. P., \& Fung, W. Y. W. (2007). Evaluation of the Native-speaking English Teacher Scheme for Primary Schools in Hong Kong 2004 - 2006. The University of Melbourne.

JET Program home page. (2012). Retrieved November 12, 2012, from http://www.jetprogramme.org/index.html

Joong Ang Daily. (2009). 100 Indians to be recruited as assistant English teachers. Retrieved November 18, 2012, from http://joongangdaily.joins.com/article/view.asp?aid=2912403

Kachi, R., \& Lee, C. (2001). A tandem of native and non-native teachers: Voices from Japanese and American teachers in the EFL classroom in Japan. Paper presented at the 2nd International Conference on Language Teacher Education, Minneapolis, MN. (ERIC Document Reproduction Service No. ED 478746 )

Lin, Y. C. (2001). Wai Ji Jiao Shi Dan Zan Hsin Chu Shi Guo Hsiao Ying Yu Jiao Hsue Chi Yien Jiou [A study of the employment of foreign English teachers by Hsinchu City as English teachers at elementary schools]. (Unpublished masters' thesis, National Hsinchu Teachers College, Taiwan).

Luo, W.-H. (2010). Collaborative Teaching of EFL by Native and Non-native English-speaking Teachers in Taiwan. In A. Mahboob (Ed.), The NNEST Lens: Non Native English Speakers in TESOL (pp. 263-284). Newcastle upon Tyne, UK: Cambridge Scholars Publishing.

Ministry of Education, Taiwan. (2003). Yin Jin Ying Yu Wai Ji Shi Tzy Cheng Tse Mu Biao Yu Chi Hsing Ji Hua Chung An Bao Kao [Report on the project of recruiting native English-speaking teachers: Policy goals and implementation]. Retrieved November 28, 2012, from http://www.edu.tw/content.aspx?site_content_sn=1367

NET Deployment Guidelines. (2009). Retrieved November 12, 2012, from http://www.edb.gov.hk/FileManager/EN/Content_7419/english.pdf

Peng, S. T. (2003). Wai Lai De Ho Shang Bi Jiao Huei Nian Jing: Tsung Hsin Chu Shi Chung Wai Ji Jiao Shi Hsie Tung Jiao Hsue De Kun Nan Yu Chan Yi Tan Chii [Monks from abroad are better preachers?: Difficulties and issues of foreign teachers' collaborative teaching in Hsin-Chu City]. (Unpublished masters' thesis, National Taiwan University, Taiwan).

Sommers, S. (2012). Why native speaker teacher programs don't work? Retrieved November 10, 2012, from http://scottsommers.wordpress.com/why-native-speaker-teacher-programs-dont-work/

\section{Appendices}

A. Interview Protocol

The first interview

1) What do you think about your collaboration with the NEST (e.g., pleasant, satisfactory, struggling, etc.)? Please give examples.

2) Can you apply what you have learned about collaborative teaching to your class and how? Please give examples. 
3) Have you followed any collaborative teaching models that you think helpful for your teaching? If yes, please give a description of the model(s).

4) What were the tasks or activities you designed for this class?

5) Did you plan the tasks or activities with the NEST before the class? If yes, how did you plan together?

6) Were there any difficulties when you carried out the activities? If yes, how did you cope with them?

7) Did you discuss the outcome of the lesson with the NEST after the class? If yes, how did s/he react to your opinions?

8) How did you feel about the collaborative teaching experience in this class? Was it great, successful, unsatisfying, frustrating or else? (Please give examples)

9) What is the students' reaction to the NEST's teaching?

10) What will you do to improve your next class?

The second and third interviews

1) What were the tasks or activities you designed for this class?

2) Did you plan the tasks or activities with the NEST before the class? If yes, how did you plan together?

3) Were there any difficulties when you carried out the activities? If yes, how did you cope with them?

4) Did you discuss the outcome of the lesson with the NEST after the class? If yes, how did s/he react to your opinions?

5) How did you feel about the collaborative teaching experience in this class? Was it great, successful, unsatisfying, frustrating or else? (Please give examples)

6) What is the students' reaction to the NEST's teaching?

7) What will you do to improve your next class?

B. Observation Focus

1) During the opening procedure, what do the teachers do to engage the students in learning?

2) During the lesson, how do the NEST and local English teacher interact with each other? How do the teachers interact with the students?

3) How do the teachers work together to give the lesson or structure activities?

4) How are the activities and students connected?

5) During the closing procedure, what do the teachers do to wrap up the lesson?

\section{Note}

Note 1. As of 2005, the starting year of English instruction at school has been changed to grade three. Yet, in some major cities in Taiwan, formal English instruction starts at grade one.

\section{Copyrights}

Copyright for this article is retained by the author(s), with first publication rights granted to the journal.

This is an open-access article distributed under the terms and conditions of the Creative Commons Attribution license (http://creativecommons.org/licenses/by/3.0/). 